\section{La moda femenina española en el Siglo de las Luces: concepto y diseños}

Bárbara Rosillo ${ }^{(1)}$

Resumen: Las cartas de dote y los inventarios de bienes constituyen una herramienta esencial para el estudio de la indumentaria a lo largo de la Edad Moderna. Esta tipología documental arroja un valioso caudal de información acerca de los usos suntuarios, confirmando la crucial importancia de la moda como signo diferenciador de estatus y su alto costo en comparación con otros elementos del ajuar doméstico. A principios del siglo XVIII la moda a la francesa está ya plenamente instaurada en España, lo que supone una drástica transformación en el atuendo femenino, no solamente a nivel formal, sino a su propia concepción.

Palabras clave: moda - indumentaria - dote - ajuar - lujo - mujer - costumbres - sociedad - Siglo XVIII - Sevilla - Andalucía - España.

[Resúmenes en inglés y portugués en las páginas 210-211]

(1) Licenciada en Historia del Arte, Universidad Complutense, Madrid. Doctora en Historia del Arte con calificación de sobresaliente cum laude, Universidad de Sevilla. Diplomada en Anticuariado, Escuela de Arte y Antigüedades, Madrid. Diploma de Estudios Avanzados (DEA), Universidad de Sevilla. Cuenta con varias publicaciones internacionales y La moda en la sociedad sevillana del siglo XVIII. Ganadora del accésit en la sección Arte del Concurso de monografías Archivo Hispalense 2016.

\title{
Introducción
}

La moda surgió en Europa durante la Baja Edad Media. Se trata de un fenómeno eminentemente urbano fruto de un grupo social que ha alcanzado un determinado bienestar y que aspira a distinguirse. Desde la más remota antigüedad el ser humano ha manifestado su deseo de superioridad, un anhelo que se puede materializar a través de un determinado modo de vida. En palabras de Sempere y Guarinos, 
En un estado, en donde, siendo todos los hombres iguales por naturaleza, su constitución los hace muy desiguales; en donde, por lo general, los medios para subir a otra clase superior no son la moderación y la virtud sino las riquezas o los empleos; en donde se aprecian los hombres, no por sus prendas y su conducta, sino por su porte exterior; y finalmente, en dónde ir bien vestido es una de las circunstancias, que más se atienden para ser bien recibidos hombres, mujeres, en las concurrencias públicas y privadas (1788, p. 199).

La manera de vestir se encuentra en íntima conexión con cada época, siendo un referente de crucial interés para comprender las aspiraciones y motivaciones de la sociedad. La indumentaria en sí misma encierra una serie de claves que ponen de manifiesto la sensibilidad, el gusto, los avances tecnológicos e incluso, los cambios políticos. Evidentemente, el primer cometido del vestido es cubrir y proteger el cuerpo. Si nos paramos a reflexionar, nada hay más cerca de nosotros que la ropa en el mundo tangible que nos rodea. Ambos, cuerpo y traje, se funden, dando lugar a la imagen que el individuo proyecta al exterior. El traje es un símbolo en sí mismo y un espejo de nuestra cultura.

A través de los siglos comprobamos que la indumentaria ha jugado con las apariencias con el fin de alcanzar determinados fines. Las siluetas masculina y femenina han sido alteradas potenciando formas y volúmenes, a veces inexistentes, pero que responden a conceptos de poder o belleza en boga. La ropa ha representado un magnífico vehículo para mostrar la posición social. Sus formas y ornamentos han llevado aparejados, en ocasiones, un lenguaje corporal propio con el que las élites se distinguían de la gente del común. En las clases privilegiadas la indumentaria ocupaba un lugar relevante y a ella se destinaba una sustancial cantidad de recursos económicos y de tiempo, fundamentalmente en el caso de las damas. En este sentido, debemos recalcar que la mujer ha tenido un papel protagonista en el desarrollo del lujo, según la célebre frase de Francisco I de Francia: una corte sin mujeres es como un jardín sin flores. La corte giraba alrededor del monarca y su familia y los nobles que les rodeaban debían seguir unas reglas, entre las cuales el gasto era obligatorio. A principios del siglo XVIII las manifestaciones artísticas se alejan de la solemnidad del Barroco evolucionando hacia formas más livianas con una destacada inspiración en la naturaleza. A lo largo de las décadas centrales del Siglo de las Luces flores y plantas jugaron un destacado protagonismo en la moda, la pintura, la decoración de interiores y las artes decorativas. Los usos en vestimenta entraron en una dinámica de sofisticación y fantasía, tanto para hombres como para mujeres. La moda femenina sufrió un proceso de aceleración, fruto del cual llegaban al mercado novedades constantes demandadas asimismo por unos nuevos usos sociales en los que las damas jugaron un papel destacado, como, por ejemplo, el de constituirse como anfitrionas de los célebres salones. El salón fue un nuevo espacio de sociabilidad que surgió en Francia en el siglo XVII con un amplio desarrollo posterior y que se exportó a otros países (Craveri, 2004). La moda va de la mano del poder, al tiempo que la nobleza pretendía mantener sus símbolos de reconocimiento, pero según expresaba König, 
Como la burguesía constantemente le sigue de cerca, ella tiene que recurrir continuamente a nuevos medios de distinción para continuar destacándose. Con ello, vuelve a acelerar el ritmo del movimiento de la moda y los cambios de estilo se suceden con cada vez mayor rapidez (2002, p. 163).

La alta sociedad expresó a través de la indumentaria el espíritu de la época, un cierto hedonismo indolente que se tradujo en creaciones de gran belleza y notable complejidad. Como afirma Flügel,

El siglo XVIII fue un periodo de artificialidad y refinamiento durante el cual la brillante liturgia de la vida de la corte mantuvo un poderío indiscutido. Los colores vívidos fueron proscritos en favor de los tintes pálidos y de polvo. En su magnificencia algo exótica, el vestido guardaba muy poca semejanza con la forma humana real (2015, p. 134).

De hecho, la nueva moda potenció las curvas de la silueta femenina, mientras que la piel comenzó a mostrarse generosamente en escote y antebrazos. Por su parte, las faldas, brotando de cinturas de avispa, aumentaron sustancialmente la anchura de las caderas. La cintura estrecha ha representado siempre un ideal de belleza femenina, salvo en muy breves periodos, ideal que perdura hasta la actualidad.

Desde finales del siglo XVII, y a lo largo de todo el XVIII, el gusto francés marcó la pauta en toda Europa. Hacia 1707 la implantación de la nueva moda en España era un hecho. La indumentaria de la mujer sufrió una notable transformación no sólo en cuanto al diseño, sino en lo referente al concepto. En España la moda femenina de los Austrias se había caracterizado por cierta rigidez. Las formas del cuerpo se hallaban ocultas bajo una ropa que las disfrazaba y comprimía, los trajes eran cerrados y los chapines los cuales eran calzados de altas plataformas, que imprimían a las damas un movimiento lento que se denominó paso de procesión. Los retratos de reinas, infantas y damas principales nos muestran a mujeres con torsos planos y pesados guardainfantes que parecen encerradas en estuches. En el siglo XVIII, tal y como veremos a continuación, la mujer también se hallaba constreñida por el traje, pero el ideal de belleza cambia, no solamente por el hecho de enseñar más piel, sino debido a que este novedoso patrón escenifica una imagen más sensual de la mujer no solamente en su indumentaria, sino en la manera de ocupar el espacio y el movimiento que los nuevos vestidos proyectan.

Con el fin de aproximarnos a la indumentaria femenina en la España del siglo XVIII, haremos un sucinto repaso de las distintas piezas y atuendos que usaron las mujeres de toda la escala social partiendo de los datos extraídos de cartas o recibos de dote, capitulaciones matrimoniales e inventarios de bienes consultados fundamentalmente el Archivo de Protocolos de Sevilla. Para una mayor claridad argumental, comenzaremos nuestro análisis de dentro a fuera, es decir, de la ropa interior a los diferentes vestidos, para finalizar con las prendas exteriores y los complementos. 


\section{Ropa interior}

La ropa interior era una partida básica en los ajuares y constaba básicamente de dos piezas: camisa y enaguas. El Tesoro de la Lengua Castellana (1611) define camisa como: la vestidura de lienzo que el hombre trae debajo de la demás ropa, a raíz de las carnes, es decir, la primera prenda en contacto con la piel, siendo además la encargada de recoger la suciedad corporal. La noción de la higiene era deficiente y las partes del cuerpo a la vista sí se lavaban; pero el baño por inmersión no era costumbre, ya que se tenía por cierto que el agua caliente al abrir los poros de la piel, dejaba a la persona expuesta al contagio de enfermedades. La camisa era blanca, se consideraba una segunda piel y se lavaba. Existen documentos en Sevilla que recomendaban mudarla al menos una vez a la semana. La documentación analizada nos indica que, aunque camisa y enaguas eran una partida fija en el ajuar, no aparecían en cantidad salvo en contadas ocasiones. Las mujeres más pudientes usaban camisas de lino o lienzo muy fino como la bretaña y la holanda, que en los ejemplos más ricos se guarnecen con encajes, labor que disparaba el precio de la prenda. También era frecuente que el cuerpo del vestido se confeccionará con un tipo de lino y las mangas con otro. En la dote de una dama noble fechada en 1764 las camisas de holanda tienen cinco varas ${ }^{1}$ de tela y se valoran a 150 reales la unidad ${ }^{2}$, precio similar al par de enaguas del mismo material ${ }^{3}$. Las camisas se podían fabricar con diferentes clases de lino, pero las enaguas se confeccionaban con distintos materiales, decoraciones y colores. Hemos hallado ejemplos de enaguas realizadas en diversos materiales, desde linos a telas más abrigadas y decoradas con todo tipo de guarniciones, como galones, cintas o flecos (Rosillo, 2020).

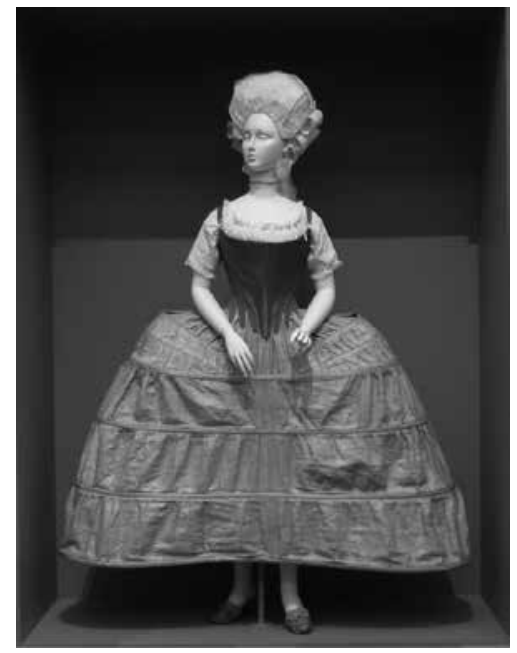

Figura 1. Camisa, cotilla y tontillo. Hacia 1780. Fuente: LACMA. LA. 
Sobre la camisa la mujer usaba el corpiño o la cotilla. El corpiño es definido en el Diccionario de Autoridades (1729) como Almilla, que es un jubón sin mangas. Generalmente el corpiño se entendía por un cuerpo sin emballenar confeccionado con lienzo blanco, aunque también podía ser de colores. El corte de la prenda era ceñido al pecho y estaba formado por cuatro hojas, dos delanteros y dos traseros con costura en el centro. El corpiño precisaba de muy poca tela para ser confeccionado. A juzgar por la información que hemos manejado, se trataba de una prenda económica. Por poner un ejemplo, la futura esposa de un maestro zapatero llevaba en su ajuar en 1719 ocho corpiños tasados en 26 reales, (Rosillo, 2020).

La cotilla era un corpiño emballenado. La voz cotilla no aparece en el Tesoro de la Lengua Castellana. La palabra proviene de cota, arma defensiva para proteger el cuerpo. Esta pieza aparece registrada en la Pragmática de Tasas de 1627, donde se especifica que los sastres españoles las fabricaban sencillas y lujosas. En la obra de Martín de Andújar Geometría y trazas pertenecientes al oficio de sastres, impresa en la Imprenta Real y publicada en 1630, aparecen patrones de la cotilla a la que también se denomina justillo, y en ambos casos son piezas sin mangas. Su confección era compleja. En un primer momento fue realizada por sastres para posteriormente correr a cargo del gremio de cotilleros. El Diccionario de Autoridades (1729) la define como un jubón sin mangas confeccionado de dos telas, pespunteado y embutido con barba de ballena, sobre el cual visten las mujeres el jubón o también llamado casaca que es ajustado al cuerpo. La cotilla era un corpiño con ballenas que se colocaba sobre la camisa, levantaba y ensalzaba el pecho, estrechaba la cintura y se ataba con cintas por detrás o por delante. Si se cerraba por la espalda, la señora precisaba de ayuda para poder vestirse, aunque es probable que solamente fuera utilizada por mujeres que no realizaban trabajo físico, ya que no facilitaba el libre movimiento. La pieza solía ser muy abierta en la parte del busto, muchas veces la zona del escote se reforzaba con piel en el borde, siendo el escote cuadrado o redondo por el que asomaba el nacimiento del pecho y la guarnición de la camisa. A partir de la cintura se remataba en recto o en faldillas sueltas. Durante el siglo XVIII, y siguiendo la costumbre francesa, mujeres y algunos hombres y niños llevaban corpiño con el fin de mantener la espalda derecha y los hombros un poco hacia atrás, postura considerada sinónimo de clase alta. En nuestro caso no hemos hallado tales piezas destinadas a uso masculino. Se sabe que algunos militares usaron corsé, aunque esta curiosa práctica se extendió a principios del siglo XIX de la mano de los dandys. Las caricaturas que se publicaron sobre el asunto nos indican que algunos caballeros, esclavos de la última moda, usaron apretados corsés también en España (Steele, 2003).

Volviendo a la cotilla, debemos precisar que también fue usada por mujeres embarazadas y lactantes. Para tal fin se ideó un orificio que lo posibilita. El Museo del Diseño de Barcelona custodia una interesante colección de cotillas, entre las cuales destacan por su rareza varias piezas de lactancia. Desde la Edad Media las damas habían usado cuerpos ceñidos para afinar su silueta, pero a finales del siglo XVII los viajes transoceánicos descubrieron las posibilidades de las barbas de ballena aplicadas a la fabricación de la ropa interior. De hecho, el mismo Diccionario de Autoridades (1729) define ballena como el ajustador que traen las mujeres, que por otro nombre se llama cotilla. Es una ballena, porque se compone y hace de las barbas de este pescado. Las barbas de ballena fueron muy demandadas en lencería y en la fabricación de sombrillas, ya que eran una de las escasas materias flexibles 
que se conocían en aquella época. Igualmente se usaron para fabricar los ahuecadores de faldas, aunque por extensión se denominaron ballenas a otros materiales como mimbre, metal, cuero o madera. La cotilla desembocó en el corsé, la primera pieza de ropa interior femenina producida a gran escala. Su vida fue larga hasta que el modisto francés Paul Poiret abogó por su supresión a principios del siglo XX.

Las piernas se cubrían con medias. El origen de esta prenda se remonta a las medias calzas, piezas que usaban hombres y mujeres hasta la rodilla. La confección adaptada a la silueta de la pierna surgió en Italia durante el siglo XVI, desde donde pasó a Francia y España. En un primer momento su producción corría a cargo de los boneteros, que las fabricaban en telar manual. Las medias se confeccionaban en diversos tejidos y colores, siendo las más apreciadas las de seda. Estas fueron un complemento básico en la indumentaria de ambos sexos, no solamente como abrigo de las piernas, sino para ir bien vestido según los cánones de la época. Las mujeres utilizaban ligas por encima de la rodilla para sujetarlas, tal y como nos muestran algunas pinturas y grabados de la época. Las ligas confeccionadas con materiales lujosos las puso de moda la corte francesa Catalina de Medicis. Las ligas podían decorarse con cintas y encajes, en algunos casos a juego con otros elementos de la indumentaria, como los encajes de la camisa o de la cofia. Las medias de seda eran las más codiciadas y parece ser que eran del todo imprescindibles en el atuendo de una dama elegante. En ocasiones se decoraban con bordados de flores, ramas o dibujos en la cara exterior por encima del tobillo, según apreciamos en algunos modelos que se conservan en distintos museos y en diversas pinturas de la época. Las denominadas cuchillas aludían a los dibujos simétricos y paralelos que se bordaban en las medias, siendo las más lujosas las que se bordaban con hilos de plata. En un inventario de 1709 aparecen doce pares de medias bordadas con cuchillas de tisú y seis pares de ligas bordadas y guarnecidas de encaje blanco. A partir de la década de 1770 se producen una serie de cambios en lo que respecta a la moda femenina. La introducción del vestido a la polonesa trajo consigo un acortamiento de las faldas, lo que propició que el calzado y el tobillo quedarán al descubierto, razón por la cual las medias tomaron un mayor protagonismo al quedar a la vista en parte. Podemos afirmar que las medias son un elemento común en prácticamente todas las cartas de dote, incluso de mujeres modestas, pero no en cantidad. En los ajuares, al igual que las demás prendas, podía especificarse que habían sido usadas, por lo que su tasación era menor. Las de seda aparecen con relativa frecuencia bordadas, pero también las de lana se decoraban. Las de color rojo son una constante durante buena parte del siglo XVIII, mientras que las negras se usaban en periodos de luto. En Sevilla a finales del siglo XVIII, un par de medias de seda costaba unos 34 reales, mientras que las de hilo unos 15 reales y las de algodón sobre 10, Rosillo (2020).

\section{El traje}

En cuanto al vestido femenino debemos precisar que en España fue muy habitual el traje formado por dos piezas: casaca y basquiña. La primera era una chaqueta entallada que llegaba hasta las caderas, por cuyas mangas asomaban los volantes de la camisa que en 
los casos más lujosos eran de encaje. El petillo era la pieza rígida que cerraba la casaca. Su frente solía presentar decoraciones y se colocaba desde el escote a la cintura. El Diccionario de Terreros (1797) lo define como: una tela que suele ser bordada, de forma triangular, que se ponen las mujeres en el pecho encima de la cotilla y justillo. La moda marcaba escotes despejados, por lo que este podía cubrirse con una especie de pañuelo llamado bobillo, generalmente de seda.

La basquiña y la saya fueron los tipos de falda más comunes y habitualmente se confeccionaban a juego con la casaca. El guardapiés o tapapiés era una falda larga, por cuyo nombre conocemos su función. En España estaba muy mal visto que los pies femeninos quedarán al descubierto, algo que se entendía como pecaminoso. Según hemos podido comprobar, el guardapiés era normalmente la pieza más costosa, ya que para su confección se destinaban materiales y adornos lujosos como seda, raso, encajes o guarniciones de plata entre otros. A finales del siglo XVIII, la española comenzó a uniformarse para salir a la calle, usando mantilla y una basquiña negra y larga sobre el resto de la ropa, que una vez en casa se retiraba. Esta prenda fue algo consustancial a todas las clases sociales, por lo que en los paseos de las ciudades se apreciaba cierta similitud en la vestimenta femenina. Dicha costumbre, de la que se hicieron eco algunos viajeros extranjeros, pervivió hasta el siglo XIX, tal y como nos relata el inglés Richard Ford (1844). La saya y la mantilla son para la mujer española lo que el buen caldo y los chalotes para el cocinero francés: que la materia prima, sea la que fuere, se aliñe con esta mágica sauce piquante y se habrá preparado en un momento una sabrosa entrée; la andaluza, cuando está en casa, donde sólo su marido la ve, es una cenicienta en el desaliño, y apenas hace otra cosa que ponerse la enagua exterior y el velo, y ya está lista para ir a la iglesia. Las niñas pequeñas de buena familia se arreglan también con la misma rapidez, y en realidad no son otra cosa que reediciones divertidas de sus madres. En cuanto a los vestidos enteros, el modelo por excelencia del periodo fue el vestido a la francesa, denominado bata en España por su apariencia engañosamente suelta. Considerado la cumbre de la elegancia femenina, y aunque no se trataba de un traje de corte propiamente dicho, fue lucido por damas elegantes de todo el continente y también por clases menos pudientes en una versión simplificada. De hecho, la documentación y las fuentes iconográficas muestran que se trata de un vestido incluso usado por el servicio doméstico.

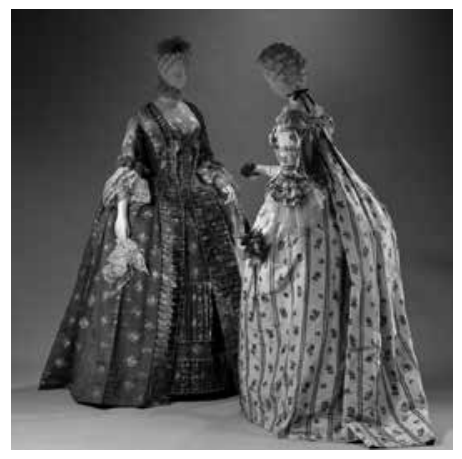

Figura 2. Vestidos

"a la francesa". 1750-1775. Fuente:

Metropolitan

Museum. Nueva

York. 
Este atuendo estaba formado por tres partes: el vestido, la falda y el peto, pero su silueta venía marcada por las piezas que se usaban por debajo. El proceso era el siguiente: sobre la camisa se colocaba la cotilla. A la altura de la cintura se disponía el tontillo, definido así por la Enciclopedia Metódica:

Se ha dado el nombre de tontillo a los aros casi redondos en figura de un arco ú de elipse más o menos ancha, que han inventado y llevado las mujeres debaxo de los vestidos de encima para darles más apariencia, haciéndoles ocupar más lugar $[\ldots]$ Se puede considerar un tontillo, sea el que fuere, como si fuera un brial más o menos largo, pero muy ancho respecto de su alto, muy plegado por arriba, donde debe abrazar justamente la circunferencia del talle, y quedar más o menos extendido hacia abajo por unas filas de ballena o de juncos cosidos a la tela del brial a cierta distancia unas debaxo de otras, y que la última sea siempre la mayor en circunferencia $(1794$, p. 56).

Este último artefacto, denominado panier en francés por su forma de cesta invertida, desembarcó en París procedente de Inglaterra en 1719 a través de un vestuario teatral. En sus comienzos, el citado ahuecador fue fabricado con hierro o madera, siendo sustituidos estos materiales más adelante por las ballenas, más ligeras y dúctiles. El tontillo era redondo y estaba formado por cinco o seis aros unidos por una tela encerada. Más adelante su forma se alteró dejando emerger todo el volumen hacia las caderas. Sobre el tontillo se colocaba un guardapiés y encima el brial, falda exterior, y sobre ello el vestido, ambos de la misma tela. El tontillo tenía unas aberturas para albergar bolsillos, denominados faltriqueras. La parte delantera de la falda que quedaba a la vista solía decorarse al igual que el frente del vestido, siendo muy frecuente una ornamentación en forma de pliegues. Para cubrir el frente del torso se colocaba el petillo denominado en francés pieza de estómago. Tal y como hemos explicado anteriormente, el petillo también cerraba las casacas femeninas. Lo define el Diccionario de Autoridades (1737) como un pequeño peto o tela cortada en triángulo, que las mujeres delante del pecho como adorno. Dicha pieza se unía al cuerpo del vestido mediante alfileres.

En cuanto a las mangas, se denominaban de pagoda. Eran ajustadas y se ensanchaba a la altura del codo, a veces rematadas con amplias vueltas, desde donde emergían tres volantes, los más lujosos de encaje, quedando el antebrazo al descubierto. La particularidad del vestido a la francesa radicaba en los pliegues que emergían de la parte superior de la espalda, llegando al suelo y desembocando en una pequeña cola. Hacia 1730 estos pliegues eran anchos, los cuales a menudo se rellenaban con lana para darles volumen, pero paulatinamente fueron estrechándose y perdiendo su empaque. Las batas se confeccionaban con todo tipo de textiles desde lienzo pintado a costosas sedas bordadas como el satén, el tisú o el espolín. En ocasiones los documentos nos informan de las batas con sus tontillos correspondientes. La hija de los marqueses de Peñaflor aportaba en su dote dos batas guarnecidas con blondas valoradas en más de 1.000 reales cada una, acompañadas de su correspondiente tontillo tasado en 120 reales $^{4}$.

A pesar de todo lo anteriormente expuesto, el vestido a la francesa nació como un atuendo informal llamado robe volante o robe battante, una especie de bata suelta con pliegues a la 
altura de la espalda que caía desde los hombros al suelo en forma de campana usado en el espacio doméstico. Han sobrevivido muy contados ejemplares de este modelo. El Palais Galliera de París conserva dos. Las fuentes consideran que fue ideado por la marquesa de Montespan, favorita de Luis XIV entre 1667 y 1679, para tratar de ocultar sus continuos embarazos. Según una crónica, en la corte de Versalles se comentaba que cada vez que Madame de Montespan se ponía su túnica battante, se creía que estaba embarazada. Este modelo, que fue popular a principios del siglo XVIII como traje de maternidad, también se conoce modernamente como vestido Watteau por aparecer en diversas obras del célebre pintor francés.

Los trajes a la francesa alcanzaron una gran belleza, siendo su silueta uno de los paradigmas del Rococó. Madame de Pompadour, la favorita de Luis XV, luce este modelo en varios retratos, siendo uno de ellos particularmente interesante, ya que a su lado se encuentran varios volúmenes del Diccionario razonado de las ciencias, las artes y los oficios, más conocido como la Enciclopedia Francesa que ella misma patrocinó, una ingente obra cuyo objetivo fue aglutinar y divulgar todos los saberes de la época. De hecho, los patrones de este traje figuran entre sus páginas. La Enciclopedia francesa destinó un tomo a las artes del vestido, donde se exponen y explican los patrones de todas las prendas. Hay incluso un capítulo entero dedicado a los botones, un elemento importante en la ornamentación, especialmente en las casacas. El vestido a la francesa estuvo vigente entre 1715 y 1775 aproximadamente y tuvo una versión más sencilla que se denominó media bata o desabillé, que consistía en un cuerpo con la misma forma que la bata, pero que llegaba a la altura de las caderas.

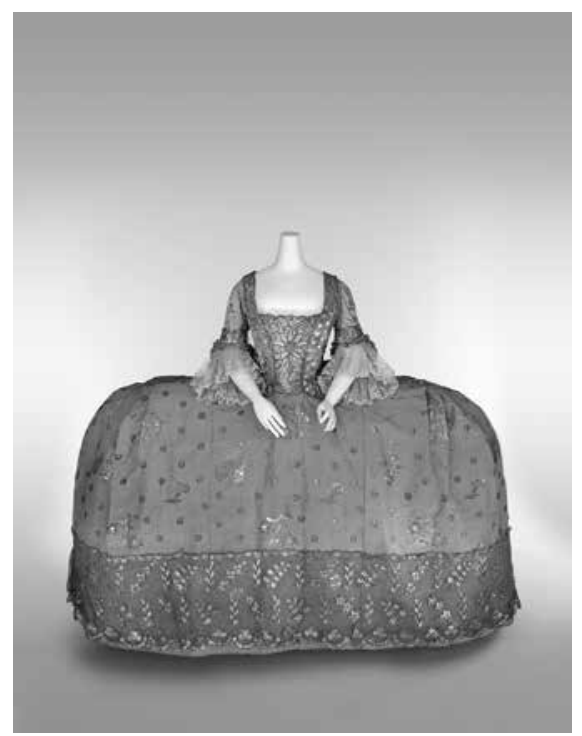

Figura 3. Vestido de corte. Hacia 1750. Fuente: Metropolitan Museum. Nueva York. 
El traje más opulento que hemos hallado fue el denominado traje de corte, sobre el que constan dos menciones en la documentación revisada. La primera se encuentra en el ajuar de Inés María de Barradas, hija de los marqueses de Peñaflor, que incluía tres vestidos de corte, siendo el principal de tisú de oro con guarnición de encaje de oro y flores sobrepuestas y compuesto por jubón, casaca, falda y guardapiés tasado en 15.000 reales $^{5}$. El segundo vestido es el que aparece en las capitulaciones matrimoniales de Isabel de Hoces y está formado por jubón, casaca y falda de medio tisú "campo de plata, flores de oro y guarnecido con punta de oro" (Archivo Municipal de Écija, 1768, p. 463) valorado en 8.713 reales $^{6}$. El vestido de corte era un atuendo ostentoso y al alcance de muy pocas mujeres que se utilizaba en ocasiones muy formales, normalmente asociadas con determinados actos y ceremonias cortesanas. Los que han pervivido impresionan tanto por sus dimensiones como por su riqueza. El tamaño de las faldas causaba todo tipo de inconvenientes, ya que las damas solo podían cruzar las puertas o espacios estrechos de una en una y probablemente de lado. Incluso en la corte francesa el primer ministro se vio obligado a intervenir para sentar a las damas a una determinada distancia unas de otras según su categoría con el propósito de que la reina, María Lezinska, no quedará oculta entre tantos miriñaques (Boehn, 1928). El vestido a la polonesa fue otro atuendo femenino en boga a finales del siglo. Su creación se debe a Rose Bertin, una marchante de modas de origen humilde que se convirtió en la modista estrella de María Antonieta. La reina de Francia fue un icono absoluto de la moda y la principal embajadora del gusto francés. Su estilo y preferencias marcaron la época. Rose Bertín, que llegó a ser apodada ministra de la moda, trabajó para ella durante años ideando una serie de atuendos y complementos, entre los que cabe destacar el citado modelo. El término polonesa deriva del uso de estilos procedentes de Polonia. Es posible que inicialmente aludiera a decoraciones sobre piel o a la costumbre de llevar subido un lado de la falda, una moda polaca que provenía de Turquía. Conocidos con diferentes nombres, a la polonesa, a la circasiana o a la turca según las escasas variaciones en su diseño, se trataba de vestidos cuyas características comunes eran un cuerpo ajustado con escote redondeado y falda con sobrefalda sobre un miriñaque en forma de tonel; todo ello con gran cantidad de adornos en los extremos de mangas, cuerpo, falda y sobrefalda, las cuales dejaban a la vista los pies. A principios de la década de 1770, la polonesa fue un vestido cortado en cuatro partes, dos en el delantero y dos en la espalda, en el que la sobrefalda se recogía por medio de alzafaldas en la parte posterior formando tres paneles drapeados de diferentes larguras. Algunos historiadores sostienen la teoría según la cual el significado de estos tres pliegues pudiera simbolizar la partición de Polonia en 1772 entre Austria, Prusia y Rusia. La particularidad estribaba en que la sobrefalda era recogida en dos o más secciones de tela drapeada con forma de conchas. Poseía además un mecanismo a base de cordones insertados en las costuras del cuerpo que ofrecía la posibilidad de alzar o dejar caer la sobrefalda. El volumen, por tanto, se centraba en la parte posterior, por lo que la polonesa se considera el antecedente de los polisones del siglo XIX. El peinado característico de este atuendo se denominó pouf.

Hacia 1770, fecha de la boda de la archiduquesa María Antonieta con el Delfín, los peinados femeninos, que habían sido sencillos en las décadas anteriores, comenzaron a tender a la verticalidad y a complicarse mediante la introducción de adornos como flores, cintas, plumas y grandes cofias. En la coronación de Luis XVI, celebrada el 11 de junio de 1775, 
la flamante reina, de tan solo 19 años, se vistió al estilo del momento con un modelo de la mano de Rose Bertín, pero fue su peinado alto, empolvado y coronado por un racimo de plumas, lo que llamó poderosamente la atención. El exagerado tocado, aunque en un principio causó un gran estupor, se puso rápidamente de moda en Francia para pasar a otros países europeos, tal y como podemos apreciar en retratos femeninos de Gainsborough, Goya o Roslin. La creación del pouf se debe a la colaboración entre Rose Bertin y monsieur Léonard, peluquero de cabecera de la reina. El pouf, además de encarnar la extravagancia, se convirtió en un medio de expresión y comunicación. Era un peinado efímero, complejo y costoso que requería horas de trabajo. Estaba compuesto por el propio cabello natural endurecido con pomadas en el que se introducía un cojín, postizos y todo tipo de ornamentación. Las marchantes de moda, una nueva profesión hija de su tiempo, jugaron un papel clave en la decoración de estas complejas estructuras. Dichos tocados fueron objeto de una imaginación incesante desarrollando las más sofisticadas tipologías, entre las que caben destacar el pouf sentimental y el circunstancial.

El vestido a la polonesa estuvo de moda aproximadamente entre 1770 y 1785, y fue usado por señoras elegantes de toda Europa. En nuestro caso particular hemos encontrado polonesas confeccionadas con todo tipo de materiales, desde linos a sedas: una polonesa de hilo y seda con guarniciones de gasa y blondas a estrenar en cuatrocientos sesenta reales; una polonesa de bretaña con cinco varas de bretaña con encajes en ciento once reales. En una dote de 1788 figura una polonesa de raso a rayas color encarnadino bordada de gasa de plata y blondas valorada en 600 reales a juego con unas joyas de Francia; estas eran bisutería y aparecen con mucha frecuencia en España.

Otro de los atuendos femeninos que estuvo de última moda hacia finales del siglo fue el vestido a la inglesa que en España recibió el nombre de vaquero. Se trataba de un modelo más sencillo compuesto por un traje entero sobre una falda diferente. Según la Enciclopedia Metódica (1797); la falda inglesa se diferencia solo por las tres costuras de la espalda que se juntan y rematan estrechándose como un vaquero redondo. Este estilo a la inglesa era de distinto color que el guardapiés; pero sin guarnición, sujetando los lados delanteros con presillas y borlas para ahuecarla, y dejar que se vea el guardapiés.

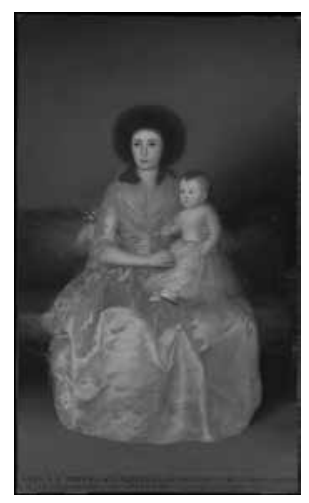

Figura 4. Francisco de

Goya y Lucientes. $\mathrm{La}$

condesa de Altamira

y su hija María

Agustina. 1787-1788.

Fuente: Metropolitan

Museum. Nueva York. 
El vaquero tenía amplio escote, mangas pegadas y una pequeña cola que emergía de los pliegues de la parte posterior de la cintura. El cuerpo de este vestido se confeccionaba aparte, se corta de muchas piezas, del mismo modo que se trazan las cotillas y cortan los corsés armándolos con ballenas muy delgadas: finalmente se pliega y se encoge la cola. El escote se cubría, en ocasiones, por medio de un pañuelo abullonado. La espalda del vaquero incorporaba ballenas por lo que se podía prescindir de la cotilla, siendo otra de sus innovaciones que este modelo permitía a la señora vestirse sola.

El último de los trajes enteros que vamos a tratar fue el denominado vestido-camisa, que en España, en ocasiones, se denominó simplemente camisa. Su origen también se encuentra en el guardarropa de María Antonieta, la reina que se sentía oprimida por la rígida etiqueta cortesana, prefería modelos algo más sencillos para su vida íntima. Por tal motivo se decantó por un traje vaporoso que recibió el nombre de camisa a la reina. María Antonieta se hizo retratar por su pintora madame Vigée Le Brun con este nuevo atuendo. El cuadro fue expuesto en el Salón de París en 1783, pero causó un fuerte rechazo por la simplicidad con la que la reina se presentaba y hubo de ser retirado. El vestido-camisa se introducía por la cabeza y se anudaba con una lazada a la altura de la cintura. Paradójicamente este modelo fue adoptado por las revolucionarias, tal y como vaticinó la revista Cabinet des modes en 1786, en este caso la moda que sus detractores han calificado de leve, inconstante, voluble y frívola, está, sin embargo, fija en sus principios. Se visualizaba cuán constante es en apoderarse de todos los acontecimientos notables, adaptándolos, registrándolos en sus anales, inmortalizándolos en la memoria popular.

En este sentido, debemos precisar que el descubrimiento de las ruinas de Pompeya y Herculano a mediados del siglo XVIII siendo rey de Nápoles Carlos VII posteriormente Carlos III de España, propició una vuelta a la antigüedad clásica. Esta tendencia, unida al estallido de la Revolución Francesa y su enconado rechazo a la estética del Antiguo Régimen, fueron los motores de un cambio absolutamente radical en la indumentaria femenina. La mujer se liberó del corpiño, las pelucas y los tacones comenzando a vestir como las estatuas clásicas. Los colores eran claros, fundamentalmente el blanco y los tejidos más vaporosos como la muselina. El calzado también se hizo a imitación de los modelos romanos y se usaron sandalias planas. El llamado estilo Imperio se decantó por siluetas sencillas con el talle bajo el pecho, brazos al descubierto y escotes despejados sobre todo para la noche. Los vestidos eran enteros y se colocaban por la cabeza o por los pies, como abrigo se usaban chales o unas chaquetillas cortas llamadas spencer. Los peinados también se decantaron por la sencillez, con simples recogidos que imitaban modelos de la Antigüedad. La maja vestida de Francisco de Goya, una de las pinturas más legendarias del momento, lleva precisamente un vestido-camisa y un spencer. 


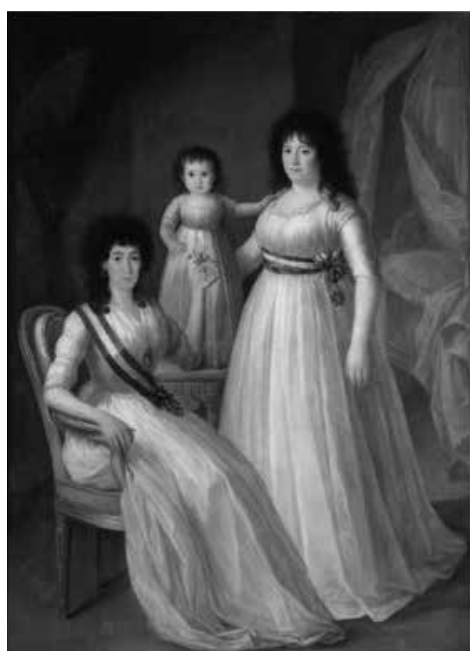

Figura 5. Agustín

Esteve. La Duquesa de Osuna y una joven, como Damas de la Orden de las Damas Nobles de María Luisa, acompañadas de una niña. 17961797. Fuente: Museo del Prado. Madrid.

\section{Prendas de encima y complementos}

En cuanto a las prendas que las españolas usaron encima del vestido en el siglo XVIII, debemos destacar en primer lugar el delantal. Este era un complemento de uso cotidiano que no solo se utilizaba para las labores caseras, sino que se convirtió en un adorno más. Las damas los lucían de telas livianas como batista, seda o muselina. A veces se guarnecían con encajes o incluso con flores artificiales. El delantal podía confeccionarse a juego con otros complementos, como aparecen en las capitulaciones matrimoniales del marqués de Alcántara del Cuervo que señalamos por su especial riqueza, por el valor de los juegos de delantal, peto, paletina ${ }^{7}$, abanicos, vuelos de encaje y bordados, 16.286 reales a lo que se añade: "otro juego de delantal, peto y paletina en 720 reales" (Archivo de Protocolos de Écija, 1760, p. 2773) ${ }^{8}$.

Para salir a la calle las mujeres se cubrían con mantos o capotillos, cuyos materiales variaban según fuese la estación, siendo el más común el paño. Pero también eran corrientes la llamada piel de liebre, mezcla de lana y pelo de cabra, y la de camello, incluso para la confección de vestidos. Los mantos iban desde la cabeza al ruedo de la falda y se ataban a la cintura con una cinta. Aparecen habitualmente en los ajuares, por lo que fue una pieza básica en el guardarropa de la española. En las personas sencillas suelen aparecen dos, uno de lana y otro más lujoso. Los más elegantes se confeccionaban con telas ligeras. El llamado de humo era negro en señal de luto, el de lustre brillante y el de soplillo muy fino, de ahí su nombre. Este tipo de denominaciones ya aparecen en el siglo XVII.

Una de las señas de identidad de la mujer española fue la mantilla. En la actualidad es un atavío que ha quedado restringido a ocasiones especiales, pero hasta mediados del siglo XIX era una pieza básica en el ajuar de cualquier mujer española. Su uso se generalizó des- 
de el siglo XVI, siendo extensivo a todas las clases sociales. Junto al rosario y el abanico, la mantilla era una pieza para salir a la calle que también usaban las niñas. Para su confección se utilizaban todo tipo de tejidos más o menos ricos dependiendo de la capacidad económica de su poseedora, desde vastos linos a finos paños, pasando por la franela, la sarga, el tafetán, la gasa, el raso o la seda. En ocasiones una misma prenda se confeccionaba con distintos tejidos, uno para el anverso y otro para el reverso; por ejemplo, mantillas de raso forradas de tafetán, incluso de colores diferentes. Para sujetarla se usaban frecuentemente broches de plata. Las damas con posibles tenían varias mantillas, y aunque nos parezca sorprendente, los colores de moda en la época eran intensos. Entre los más comunes estaban los denominados carmesí, color de fuego, encarnado, color de ámbar y el verde. El efecto de tan vivos tonos debía ser de lo más llamativo.

A mediados del siglo XVIII se impusieron los tonos pastel típicos del Rococó, como el rosa o el celeste. Y hacia 1790 se comenzó a tender hacia el blanco o el negro, siendo la muselina, tela de algodón muy liviana que provenía de La India, la gran protagonista. Para enriquecer la mantilla normalmente se guarnecía con encajes blancos o negros, por lo que su precio se disparaba, ya que la labor de los bolillos se realizaba exclusivamente a mano. Durante el siglo XVIII se produjo la gran eclosión del encaje, una moda que causó furor, siendo los más apreciados las blondas francesas y los de Bruselas, aunque también en España se elaboraban de gran calidad, sobre todo en Valencia y Cataluña. No solamente se guarnecían las mantillas con encaje, sino también con hilo de plata o con galón de oro. Las más económicas que hemos encontrado eran las de bayeta ${ }^{9}$, cuyo precio podría rondar los 10 reales. Las de raso o seda estaban entre los 60 y 200 reales, pero sin duda las más costosas eran las de encaje de blonda francés, como, por ejemplo, una mantilla de gasa negra a rayas guarnecida con blondas anchas de Francia que llegó a costar 895 reales, una cifra muy elevada. En el Romanticismo se impuso la mantilla blanca o negra y exclusivamente de encaje, al tiempo que se extendió también el uso de la peineta. La reina Isabel II las lucía con frecuencia, al igual que la noble española Eugenia de Montijo, que llevó esta costumbre a Francia al casarse con el emperador Napoleón III en 1853.

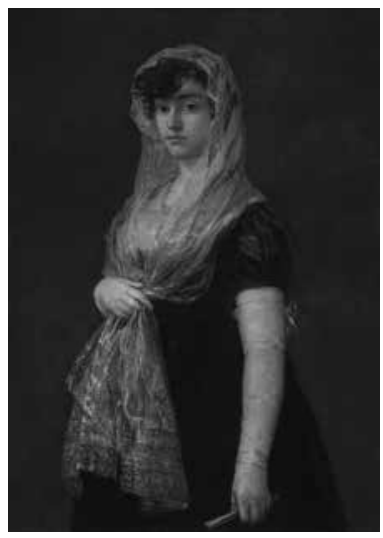

Figura 6. Francisco

de Goya. Joven

dama con mantilla y

basquiña. Hacia 1800.

Fuente: National

Gallery of Art.

Washington. 
Para cubrir la cabeza las mujeres también usaron bonetes, sombreros, cofias o escofietas, estas últimas tanto para estar por casa como para salir a la calle. El gremio de las escofieteras se dedicaba a su fabricación.

En cuanto al calzado, debemos señalar que ambos sexos usaban zapatos de tacón. Se fabricaba con telas o pieles como el becerrillo, el cordobán o la badana. Las hormas eran rectas y el pie debía ir adaptándose. Las mujeres usaban zapatos ajustados con el empeine alto cerrados mediante una hebilla de metal, siendo las más lujosas de plata e incluso de oro, y en ocasiones salpicadas de piedras semipreciosas. Las chinelas, un tipo de zapato sin talón, aparecen también con mucha frecuencia. Se usaban para estar por casa y el tacón fue bajando progresivamente a lo largo del siglo.

A través de estas páginas hemos intentado exponer de manera sucinta la indumentaria que usaron las españolas en el siglo XVIII con sus características formales y modelos principales. Hasta finales del Antiguo Régimen la moda surgió en las cortes, desde donde pasaba al resto de la población, que la adaptaba según sus capacidades. El traje fue un signo de gran relevancia en la sociedad estamental, siendo el Siglo de las Luces testigo de un fenómeno de internacionalización de la moda francesa, una moda que fue seguida incluso por sus acérrimos enemigos, poniendo en evidencia que las reglas de la vestimenta seguían otros códigos y valores. El gusto francés fue determinante en el aspecto femenino, no solo en lo que respecta a los vestidos, sino otorgando a la mujer una presencia más activa y dinámica que se tradujo en un mayor protagonismo social. Tal y como expuso nuestro célebre ilustrado el padre Feijoo en el libro de Teatro Crítico Universal,

Francia es el móvil de las modas. De Francia lo es París, y de París un Francés, o una Francesa, aquel, o aquella a quien primero ocurrió la nueva invención. Rara traza y más eficaz sin duda que aquella de que se jactaba Arquímedes, se halló para que en particular moviese toda la tierra. Los Franceses, en cuya composición, según la confesión de un autor suyo, entra por quinto elemento la ligereza, con este arbitrio influyeron en todas las demás Naciones su inconstancia, y en todas establecieron una nueva especie de Monarquía (1728, tomo segundo, discurso sexto).

\section{Notas}

1. La vara era la unidad de medida, equivalente a $0,83 \mathrm{~m}$.

2. Para tener una aproximación al coste de la vida, diremos que a mediados del XVIII el salario medio de un maestro de obras en Sevilla era de 8 reales al día. OLLERO LOBATO. F (2012): "La maestría mayor de obras de la Real Audiencia de Sevilla (siglos XVII-XIX)". Atrio.pp. 27-42.

3. Capitulaciones matrimoniales de Fernando Arias de Saavedra, marqués de Quintana de las Torres, e Isabel de Hoces. Fondo Marquesado de Peñaflor, legajo 453. Archivo Municipal de Écija. Sevilla. 
4. Fondo Marquesado de Peñaflor, de Cortes de Graena y de Quintana de las Torres. Legajo 9, año 1772, documento 10. Archivo Municipal de Écija. Sevilla.

5. El vestido se confeccionó en Madrid. Fondo Marquesado de Peñaflor. Legajo 9, año 1768, documento 4. Archivo Municipal de Écija. Sevilla.

6. Fondo Marquesado de Peñaflor. Legajo 453, año 1768. Archivo Municipal de Écija. Sevilla.

7. Adorno que se ponía en el cuello.

8. Archivo de Protocolos de Écija. Legajo 2773. Año 1760.

9. Paño de lana.

\section{Lista de Referencias Bibliográficas:}

Covarrubias .S. de (1611). Tesoro de la Lengua Castellana o Española. Madrid: Luis Sánchez. Delpierre, M. (2007). Dress in France in the Eighteenth Century. Yale University Press.

Diccionario de Autoridades. (1726-1739). https://apps2.rae.es/DA.html

Boehn, M. von (1928). La moda. Historia del traje en Europa desde los orígenes del Cristianismo a nuestros días. Tomo IV. Barcelona: Salvat Editores.

Feijoo, B. J. (1728). Teatro crítico universal. Tomo segundo. Discurso sexto. https://www. filosofia.org/bjf/bjft206.htm

Flugel, J. C. (2015). Psicología del vestido. Santa Cruz de Tenerife: Editorial Melusina.

König, R. (2002). La moda en el proceso de civilización. Valencia: Engloba Edición.

Terreros y Pando, E. de (1788). Diccionario con las voces españolas de ciencias y artes y sus correspondientes en las tres lenguas francesa, latina e italiana. Madrid: Imprenta de la Vda. de Ybarra.

Plaza Orellana, R. (2009). Historia de la moda en España. El vestido femenino entre 1750 y 1850. Córdoba: Almuraza.

Rosillo, B. (2020). La moda en la sociedad sevillana del siglo XVIII. Sevilla: Diputación de Sevilla.

Rosillo, B. (2018). “Cómo viste la nobleza? “Indumentaria y estatus social” en Nobleza e imagen: la exteriorización del estatus social (Serrera, R. (coord.). Sevilla: Real Maestranza de Caballería.

Sempere y Guarinos, J. (1788). Historia del luxo y de las leyes suntuarias en España. Madrid: Imprenta Real.

Sombart, W. (2009). Lujo y capitalismo. Madrid: Ediciones Sequitur.

Steele, V. (2005). The Corset: A Cultural History. Estados Unidos: Yale University Press.

Weber, C. (2006). Queen of fashion. What Marie Antoinette wore to the Revolution. New York: Henry Holt and Company.

Abstract: Dowry letters and property inventories are an essential tool for the study of clothing throughout the Modern Age. This documentary typology provides a valuable 
wealth of information about sumptuary uses, confirming the crucial importance of fashion as a differentiating sign of status and its high cost compared to other items of domestic trousseau. At the beginning of the 18th century, French fashion was fully established in Spain, which entailed a drastic transformation in female outfit, not only at a formal level, but also in its own conception.

Keywords: fashion - clothing - dowry - trousseau - luxury - woman - customs - society 18th century - Seville - Andalusia - Spain.

Resumo: Cartas de dote e inventários de propriedades são uma ferramenta essencial para o estudo de roupas na Idade Moderna. Esta tipologia documental fornece uma valiosa riqueza de informações sobre suntuários confirmando a importância crucial da moda como um sinal diferenciador de status e seu alto custo em comparação com outros itens de mobiliário doméstico. No início do século XVIII, a moda francesa estava totalmente implantada em Espanha, o que representa uma transformação drástica no vestuário feminino, não só a nível formal, mas também na sua própria concepção.

Palavras chave: moda - vestuário - dote - enxoval - luxo - mulher - costumes - sociedade - século XVIII - Sevilha - Andaluzia - Espanha.

[Las traducciones de los abstracts fueron supervisadas por el autor de cada artículo] 